\title{
REVISITING GROUP WORK METHOD IN THE CONTEXT OF NON-FORMAL EDUCATION
}

\author{
Anna Vintere \\ Latvia University of Life Sciences and Technologies, Latvia \\ Inese Ozola \\ Latvia University of Life Sciences and Technologies, Latvia
}

\begin{abstract}
The use of group work in non-formal education has been practiced for many years. Researchers mention that group work may be mutually beneficial for learners in terms of the acquired knowledge, however, group work participants might be carried away by dealing with relationships within the group. In recent years, various international projects of training courses for youth and adult educators choose learner-centred group work or workshop format instead of traditional teacher-centred lecturing style. Also, generation of millennials who are digital residents and are more accustomed to technologies and telephones than faceto-face interaction requires more detailed preparing of the activities of the group work. Young adults prefer to work with facilitators who are approachable, supportive, good communicators, and good motivators. According to the previous research results, during the work group learners develop critical thinking skills, time management skills, team work and presentation skills, tolerance and other skills. The present paper is an attempt to research the strengths and weaknesses of the group work method in non-formal education in the framework of two international project activities: Nordplus adult education project "Design thinking method for creative tackling unemployment" and international youth training of Erasmus+ project "You(th)r Culture". The conclusion gives the summary of the findings of the research, focusing on the benefits of using of the group work method for the multinational audience of adult educators and youth, as well as identifying the main differences in its implementation for the relevant audiences.
\end{abstract}

Keywords: critical thinking, group work, multinational audience, team work skills, time management skills, tolerance.

\section{Introduction}

The development of innovative products and processes in education, quality increase at all levels of education to tackle socio-economic changes, ensure growth, jobs, equality and social inclusion, is possible through systematics exchange of experience and good practice. That is why the European Union and other stakeholders, such as the Nordic Council of Ministers, spend an impressive budget each year on various educational issues aimed at identifying of good practice and generating new knowledge through mobility, networks and development projects. The authors of this article have 
participated in several International Education Projects, thus gaining new knowledge and experience themselves in non-formal education. This article analyses non-formal education experience in the framework of two international project activities: Nordplus adult education project "Design thinking method for creative tackling unemployment" and "You(th)r Culture", a learning mobility project of individuals in the framework of Erasmus+ programme.

Nordplus adult education project "Design thinking method for creative tackling unemployment" (2019) was aimed to adapt the design thinking method to adult learning to help reduce unemployment and encourage entrepreneurial spirit for the unemployed people as well as to help the unemployed to understand a situation, to realize their potential, to promote the spirit of entrepreneurship as a solution to unemployment as well as encourage them to acquire craft techniques (as a basis for self-employment) offered by partner training centres. The project activities also included adult teachers training on what the design thinking method was and how to apply it in practice. Adult teachers from six countries, three from each, participated in the training. It should be noted that the age of the participants was between 40 and 60 years.

Erasmus+ project "You(th)r Culture" (2019) contained a training course on tools and methods within the youth exchange in order to fight against radicalisation of young people and use cultural diversity as a positive tool of non-formal education. The overall aim of the training course was to train youth workers and youth leaders to use cultural diversity as a positive and powerful tool to build tolerance for cultural diversity and actively seek common roots across Europe, which is considered an excellent step in the fight against youth radicalization. Mostly young people aged 18-30 from ten EU countries participated in the training.

Both courses mentioned above were designed as an open learning process based on participants' experience and exchange. The training courses followed the non-formal education approach combining different creative and interactive methods. Most often training sessions were organized as a group work. In the scientific literature, group work is most often associated with methods appropriate to the education for sustainable development. Group work is also consistent with the constructivist approach to education. Group processes play an important part in determining group dynamics and effective work of the group. Groups may face the challenges of communication, problem solving, decision-making, conflict management and leadership issues (Halverson \& Tirmizi, 2008). Group work is the method of learning and form of organization of the study process that requires cooperation, interaction, and communication to complete a task. Communication is an important aspect used by group members to organize their work and cooperate with one another (Marks, Zaccaro, \& Mathieu, 2000). Spoken language is used to transform individual thought into 
collective thought and action but also to make personal interpretations of shared experiences (Mercer, 2002). The group work may be mutually beneficial for learners in terms of the acquired knowledge, but also group work participants might be carried away by dealing with relationships within the group. Group members learn a great deal by explaining their ideas to others. The group work in adult education is compared with peer learning where peers should learn from each other, and peer learning can be described as the way to moving from individual learning to interdependent or mutual learning (Boud, 1988). Thus group work is mutually beneficial and involves the sharing of knowledge, ideas and experience between participants. In addition, participants develop a range of skills during the group work: organizing, planning, working collaboratively, giving and receiving feedback and evaluating their own learning (Boud, 2001). The international projects involve multicultural teams which is an additional challenge. A meticulous study on multicultural group work in higher education by Popov et al (2011) found that free-riding, insufficient English language skills and students not communicating properly are the most challenging aspects of multicultural group work. Free-riding or not contributing equally with other members to the group work, insufficient English language skills and communication skills negatively influence the climate of the group and its overall performance.

\section{Methodology}

The methodology of this study is based on the analysis of the scientific literature. The empirical data were obtained during a focus group discussion with participants of the training sessions of the two above mentioned projects. The method of focus group discussions is used in social sciences for a number of reasons. Focus groups offer a "safe" and more informal environment where participants can share views, experience, beliefs, and attitudes in a free and opened discussion about a particular topic (Krueger \& Casey, 2015). Group dynamics during the focus group method facilitate exchange of opinions and thus allow researchers to understand meanings and interpretations of the participants. Consequently, a focus group interview was used to investigate personal experience and observations of participants of the above mentioned projects.

\section{Research results}

According to the Vygotsky (1978), one of the leading founders of constructivism, the social environment plays an important role in the development of cognition. He proved that an individual cannot thrive without 
interacting with the environment. Constructive processes are particularly powerful in a group setting where each individual has an understanding of the complex social interactions in which he or she is embedded. Vygotsky believed that knowledge begins at the social level, and only then does it become individual knowledge (Vygotsky, 1978). Constructivism assumes that learning is a social process where individuals learn through interacting with other people (Pritchard \& Woollard, 2010). To construct learning by the group, rather than just the individual, it should be designed, implemented, and then guided through the process of collaboration and interaction between learners (Fernando et al., 2005).

The importance of group work is characterized by the skills and abilities that can be developed using this method. McKinsey Global Institute workforce skills model of 25 skills presents workforce in five skill categories: physical and manual skills, basic cognitive skills, higher cognitive skills, social and emotional skills and technological skills. For example, higher cognitive skills include critical thinking and decision making, creativity, but social and emotional skills include interpersonal skills and empathy, adaptability and continuous learning. Technological skills contain (as the name suggests) basic and advanced IT skills, programming, advanced data analysis and mathematical skills (McKinsey Global Institute, 2018). In 2017 the analysis of interviews with forty company managers from four countries in the framework of the ERASMUS+ IWBLabs project revealed that they expected a wide range of skills from graduates apart from professional knowledge or the knowledge of a product. The most often mentioned skills in the order of priority were: team work, creativity, foreign language skills, IT skills, interpersonal communication skills, and problem solving skills. It was interesting to note that job-specific skills were not prevailing, but the so-called soft skills, such as problem solving skills, creativity, and team work dominated in the interviews. Company managers also mentioned personal qualities such as: responsibility, honesty, loyalty, motivation, determination and active attitude (Ozola \& Grasmane, 2019). The review of the scientific literature led to the selection of five skills that are most often cited as the outcome of group work, namely: critical thinking skills, time management skills, team work and presentation skills, tolerance.

Critical thinking is one of the analytical competence dimensions. In the context of sustainable development critical thinking is understood as the ability to challenge norms, practices and opinions. It includes also reflection on one's own values, perceptions and actions, as well as it is understanding of external perspectives (Lozano et al., 2017). Critical thinking is understood as information identification and interpretation, information analysis and evaluation of evidence and argument (Firdaus et al., 2015). Thinking critically means to make the right decision and act in time. 
Time management skills are quite similar to critical thinking, since time management also involves the analysis, planning and designing programmes, managing various resources, including information. The time management means that the time is managed efficiently and individuals perform constructive utilization of time (Karim \& Mitra, 2015). Time management activities include setting objectives, planning and prioritizing behaviours and creation of work content (Yilmaz et al., 2006), which are also elements of any group work. According to Fleming (2011), the most basic conditions of effective time management are the practice of identification of strategic tasks in an appropriate manner and the selection of appropriate tools and techniques for the completion of those tasks.

Critical thinking and time management are two skills that characterize the dimension of the cognitive process of group work, while teamwork and tolerance refer to collaboration among group members.

Tolerance means acceptance of the very things one disagrees with, disapproves of or dislikes. It concerns acceptance of the differences between others and ourselves that we would rather fight, ignore, or overcome (Van Doorn, 2014). To be tolerant means to overcome or avoid a conflict. According to Vogt (1997), tolerance is putting up with something you do not like, often in order to get along better with others. Van Doorn (2014) pays attention to three aspects of tolerance: dislike, disagreement or disapproval.

According UNESCO (1995), tolerance is necessary among individuals as well as at the level of a family and community. Promotion of tolerance and the shaping of attitudes of openness, mutual listening and solidarity should take place in schools and universities and through non-formal education, at home and in the workplace. When it comes to tolerance in the context of group work, it is an attitude that allows others to express their views that are different from your own. It requires a certain amount of spiritual freedom and the ability to understand others without considering themselves to be the only ones who are right.

The term "teamwork" can be defined as the work of a group of interdependent persons together to achieve a common goal or task in the most efficient and effective way. Teamwork relies upon individuals working together in a cooperative environment to achieve common team goals through sharing knowledge and skills (Tarricone \& Luca, 2002).

A common goal and a clear purpose are two key aspects of successful teamwork. Tarricone \& Luca (2002) mentioned such aspects as interdependence, appropriate team composition with clear member roles, relationship assignment and responsibilities, interpersonal skills as well as open communication and positive feedback for successful teamwork. The last two criteria are closely linked to the concept of tolerance characterized by the 
authors', including giving and accepting feedback, engaging in an open dialogue and communication, constructive criticism, listening to ideas and feelings of everyone, dealing with a conflict, etc.

The focus group interview analysed and compared two project seminars: adult educators and your workers and leaders. The analysis of focus group interviews revealed that the authors have identified some differences in the use of group working methods among adult educators and youth workers and leaders. As stated above, adult educators were invited to participate in a training on design thinking. Design thinking is a new pedagogical approach that is not yet sufficiently integrated into the educational process of Latvia. It is a process of changing attitudes towards traditional things by combining analytical and creative thinking, making a creation of a wide variety of innovations manageable and understandable, reviewing a case and event research, the method of idea generation, solution development and thinking management in order to achieve problem solving with maximum efficiency (Rozzuk \& Shute, 2012). The method is based on the idea that nothing should be changed at the first moment, but the time should be taken to explore, check, look at things from different angles for several times. However, it is difficult to apply this method to adult educators, especially academic staff members, as they have a solution right away when presented with a problem or a challenge. According to the outstanding Latvian pedagogical scientist Zogla (2001), teaching staff members need time to accept innovations. Teachers might encounter difficulties in the process of becoming innovative persons. It is hard to change the attitude and one's individual didactical model which has already been used and tested and which is rather stable. Although, according to Fullan (2011), teachers have to be open to new ideas, be able to adapt to changes and be flexible. One of the ways to motivate the teaching staff is through the method of collaboration and teamwork, which promotes professional development and is considered a safe way of making some changes (Fullan, 2001).

Design thinking is based on the ability to listen and explore audience's problems, needs, existing opportunities and their evaluation from a user's perspective so that the solutions that come later are really in demand. Therefore, group work for problem solving was important, and the solution, based on the knowledge or experience of an educator, directed the group to the right solution.

Another opinion that was expressed in a focus group interview concerned teaching methods of adult educators. It is not a secret that in many cases the transfer of knowledge from lecturers to students with the help of lectures as the main form of learning is still predominant. That is why educators expect lecturing as a teaching method in non-formal education. Educators might feel lost during group work activities that require an in-depth analysis of the problem and suggestion of ideas; in addition, participants have to listen to criticism of 
their opinions and to accept the views of others. Group work is about an active participation and knowledge building on the topic instead of passive participation without giving a feedback. As regards the group work in youth audience, the procedure was very smoothly worked out and the tempo of activities depended on the facilitator who divided participants into groups, stated the topic, the time limit for each activity, the method of presenting the results of the group work and the type of a feedback. The time limit for each activity was sufficient to generate ideas, listen to opinions of all group members, prepare the product to be shared with the whole audience in front of the classroom. Visualisation was mainly the method of recording the generated information supported by an oral presentation of the results of the group work. It was noted in the focus group interview that project participants from youth organizations were keen to build knowledge, share their experience, listen to others and work together to complete the task. Cases of free-riding were not observed, group members contributed equally. However, it should be noted that oral presentations were presented by the members of the whole group. The feedback was required on daily basis, as the morning sessions started with the analysis of the previous day's activities, and participants did not hesitate to express their views. The participants of the focus group interview observed that project participants were very polite, eager to listen, cooperative, involved in discussions actively, supportive and helpful.

It should be noted that youth workers or leaders who are more used to technology and telephones than face-to-face communication, prefer to work with facilitators who are approachable, supportive, good communicators, and good motivators. In contrast, groups of adult educators can organize themselves successfully, which is a great advantage for this group. As regards, adult educators, they presented the results individually, participated in the question and answer session, analysed solutions of the problems.

Although several studies have shown that there is a relationship between tolerance and educational attainment, the participants of the focus group interview concluded that young people were much more tolerant than adult educators aged $40+$. A study conducted in Britain also confirmed the view that young people are more tolerant than older people and/or previous generations (Janmaat \& Keating, 2017).

\section{Conclusions}

1. Most often group work is used in international education projects to identify good practice and create new knowledge. 
2. Group work is most often associated with methods suitable for education for sustainable development and consistent with a constructivist approach to education.

3. Critical thinking and time management are two skills that characterize the dimension of the cognitive process of group work, while teamwork and tolerance refer to collaboration among group members.

4. Young people are much more tolerant than adult educators.

5. Adult educators' advantages are the ability to organize teamwork and present results, while in the youth audience - they are able to listen to all views and reach a joint decision.

\section{References}

Boud, D. (1988). Moving towards autonomy. In Boud D. Developing student autonomy in learning. $2^{\text {nd }}$ edition, London, Kogan Page.

Boud, D. (2001). Making a move to peer learning. In Boud D., Cohen R. and Sampson J. (eds.) Peer learning in higher education: learning from and with each other (1-20). London, Routledge.

Janmaat, J.G., \& Keating, A. (2019). Are today's youth more tolerant? Trends in tolerance among young people in Britain. Ethnicities, 19(1), 44-65.

Fernando, A., Lopez, G., Manrique, D., \& Vines, J.M. (2005). An instructional model for web-based e-learning education with a blended learning process approach. British Journal of Educational Technology, 36, 219.

Firdaus, F., Kailani, I., Bakar, N.B., \& Bakry B. (2015). Developing Critical Thinking Skills of Students in Mathematics Learning. Journal of Education and Learning, 9(3), 226236, Retrieved from

https://www.researchgate.net/publication/282526043_Developing_Critical_Thinking_S kills_of_Students_in_Mathematics_Learning

Fleming, I. (2011). The Time Management Pocketbook. $6^{\text {th }}$ edition, Management Pocketbooks.

Fullan, M. (2001). The New Meaning of Education Change. New York: Teachers College Press.

Halverson, C.B., \& Tirmizi, S.A. (2008). Effective Multicultural Teams: Theory and Practice. Springer Science: Business media B.V.

Downs, D.J. (2008). Book Review: 1 Thessalonians, 2 Thessalonians, Volume 62, issue 3.

Karim, S., \& Mitra, K. (2015). Time management skills impact on self-efficacy and academic performance. Journal of American Science, 7(12).

Krueger, A.R., \& Casey, A.M. (2015). Focus Groups: A Practical Guide for Applied Research. (5th ed.). Los Angeles, London, New Delhi: SAGE Publications, Inc.

Lozano, R., Merrill, M.Y., Sammalisto, K., Ceulemans, K., \& Lozano, F.J. (2017). Connecting Competences and pedagogical Approaches for Sustainable Development in Higher Education: A Literature Review and Framework Proposal. Sustainability, 9, 1889. Retrieved from www.mdpi.com/journal/sustainability

Marks, M.A., Zaccaro, S.J., \& Mathieu, J.E. (2000). Performance Implications of Leader Briefings and Team-interaction Training for Team Adaptation to Novel Environments. Journal of Applied Psychology, 85, 971-986. 
McKinsey Global Institute. (2018). Skill Shift. Automation and the Future of the Workforce. Retrieved from //C:/Users/user/AppData/Local/Temp/MGI-Skill-Shift-Automationand-future-of-the-workforce-May-2018-1.pdf

Mercer, N. (2002). Developing Dialogues. In Wells G., Claxton G. (Eds.), Learning for life in the 21 ${ }^{\text {st }}$ century: Sociocultural Perspectives on the Future of Education (pp. 141-153). Blackwell Publishing Ltd.

Ozola, I., \& Grasmane, D. (2019). Enhancing Students' Employability Skills Through International Project IWBLabs, INTED2019 Proceedings, 9367-9374.

Popov, V., Brinkman, D., Biemans, H., J.A., Mulder, M., Kuznetsov, A., \& Noroozi, O. (2012). Multicultural Student Group Work in Higher Education. An explorative case study on challenges as perceived by students. International Journal of Intercultural Relations, 36, $302-317$.

Pritchard, A., \& Woollard, J. (2010). Psychology for the classroom: Constructivism and social learning. London: Routledge.

Razzouk, R., \& Shute, V. (2012). What is design thinking and why is it important? Review of Educational Research, 82(3), 330-348.

Tarricone, P., \& Luca, J. (2002). Successful teamwork: A case study. HERDSA.

UNESCO. (1995). Declaration of principles on tolerance. Retrieved from https://www.refworld.org/docid/453395954.html

Yilmaz, I., Oncalik, O., \& Bektas, F. (2006). Relationship between the time management behavior and academic success. E-journal of New World Sciences Academy, 5(3).

Van Doorn, M. (2014). The nature of tolerance and the social circumstances in which it emerges. Current Sociology, 62(6), 905-927.

Vogt, W.P. (1997). Tolerance and Education: Learning to Live with Diversity and Difference. Thousand Oaks, CA, London and New Delhi: Sage.

Vygotsky, L.S. (1978). Mind and society: The development of higher mental processes. Cambridge, MA: Harvard University Press.

Žogla, I. (2001). Didaktikas teorētiskie pamati. Rīga: Raka. 